\title{
湖南中-晚泥盆世腕足动物组合、海平面升降 及古地理演变
}

马学平*，宗普

北京大学地球与空间科学学院, 造山带与地壳演化教育部重点实验室, 北京 100871

*E-mail: maxp@pku.edu.cn

收稿日期: 2010-01-20; 接受日期: 2010-08-25

国家重点基础研究发展计划项目(编号: 2006CB806408)和国家自然科学基金(批准号: 40872007, 40830211)资助

摘要 湖南的吉维期至中法门亚期的腕足动物可以分为五个生物带, 自下而上为鸮头贝 (Stringocephalus) 顶峰带、双腔贝类 (ambocoeliids)-秃嘴贝类(leiorhynchids) 组合带、马石燕类 (cyrtospiriferids)组合带、准云南贝(Yunnanellina)-中国石燕(Sinospirifer)组合带、云南贝(Yunnanella)-湖南石燕(Hunanospirifer)组合带; 它们分别大致对应于牙形石Po. hemiansatus 带至Po. varcus 带、S. hermanni 带至Pa. punctata 带、Pa. hassi 带至Pa. linguiformis 带、Pa. triangularis 带至上Pa. crepida 带、最上Pa. crepida 带至P . marginifera 带. 华南泥盆纪裂谷活动的强化始于

关键词

湖南

泥盆纪 腕足动物 裂谷活动 海平面 古地理 下Po. varcus 带的中部(牙形石Po. rhenanus 的首现层位), 与国际地层委员会泥盆系分会所确认的 下-中吉维亚阶的界线一致. 牙形石 S. hermanni 带的海侵不只在广西的过渡相区中有表现, 在湖 南的台盆相区, 甚至在台地相区均可识别, 反映的应该是海平面的整体上升. 这个层位与国际地 层委员会泥盆系分会所确认的中-上吉维亚阶的界线同样一致. 虽然在吉维期末期华南的台盆相 区水体可能加深, 但台地相区可能经历了不同程度的抬升, 尤其是湖南中北部地区表现明显, 许 多地区可能缺失了弗拉斯期早期的沉积. 同样地, 弗拉斯期末期的海退造成了许多地区暴露, 并 缺失法门期早期的沉积, 从而导致了准云南贝动物群分布的局限性.

湖南中-晚泥盆世的地层十分发育, 尤其是湘中 地区, 底栖化石非常丰富, 是我国泥盆纪地层研究的 最主要地区之一. Tien ${ }^{[1]}$ 对湖南泥盆纪(主要为湘中晚 泥盆世)的腕足动物进行了广泛的研究, 并综合了湘 中泥盆纪的完整地层系统, 其中中泥盆世的地层主 要包括跳马涧系和棋梓桥系、晚泥盆世的地层包括下 部的余田桥系和上部的锡矿山系, 分别与弗拉斯阶 和法门阶对比. 20 世纪 60 70 年代的地质填图工作及
其后的一些专题研究为全面了解湖南泥盆系的发育 情况打下了扎实的基础 ${ }^{[2 \sim 5]}$. 这样, 湖南的泥盆纪地 层就比较完整地建立起来 ${ }^{[6]}$.

详细的岩相古地理研究对探讨息息相关的沉积 矿产及当地的地质发展史均具有重要意义, 这在过 去结合金属矿产、礁体等方面的研究出现了诸多成 果 ${ }^{[3,7,8]}$. 然而, 详细、系统的中-晚泥盆世湖南的古地 理样式及演变研究还比较少见. 最首要的基本问题

引用格式: Ma X P, Zong P. Middle and Late Devonian brachiopod assemblages, sea level change, and paleogeography of Hunan, China. Sci China Earth Sci, 2010, doi: 10.1007/s11430-010-4090-0 
是详细的地层对比, 这会遇到许多困难, 主要问题是 浅水相地层与深水相地层之间的对比问题, 其原因 是因为浮游生物化石分布比较局限, 在台地相区相 对罕见, 使得单纯利用这类化石难以解决大部分地 区的地层问题. 本文结合前人在湖南较深水相区及 浅水相区的地层工作，综合浮游及底栖生物化石分 带以及主要海平面变化事件, 尝试对剖面间的对比 进行新的解释和阐述, 在此基础上, 编制了吉维期至 法门期中期的六幅古地理图.

本文中, 泥盆系的亚阶划分定义与国际泥盆系 地层分会的建议一致 ${ }^{[9]}$. 牙形石属的缩写如下: Palmatolepis 缩写为 Pa.; Polygnathus 缩写为Po.; Schmidtognathus 缩写为 $S$. 图示的腕足动物标本保存 在北京大学地质档案馆.

\section{1 地质背景及剖面状况}

早泥盆世晚期, 海水自南西方向侵入湖南. 到中 泥盆世, 跳马涧组及其上的易家湾组沉积已广布于 湘中南地区，其中后者含腕足类 Stringocephalus 及珊 瑚 Endophyllum-Sunophyllum 组合. 自棋梓桥灰岩沉 积开始，华南泥盆纪的古地理格局产生了极大的变 化，这就是广西地区裂谷活动的加剧，这种活动也影 响到了湖南地区，使得湖南与广西地区的情况非常 相似，即裂谷活动的加强导致台-沟地理系统，形成 了多样的岩相分异沉积，这种状况一直持续到弗拉 斯期末期(图 1). 法门期开始，湖南地区呈现的是一 个相对均一的岩相格局，尤其是锡矿山组沉积时如 此, 其中的 Yunnanella 动物群分布广泛, 可能代表了

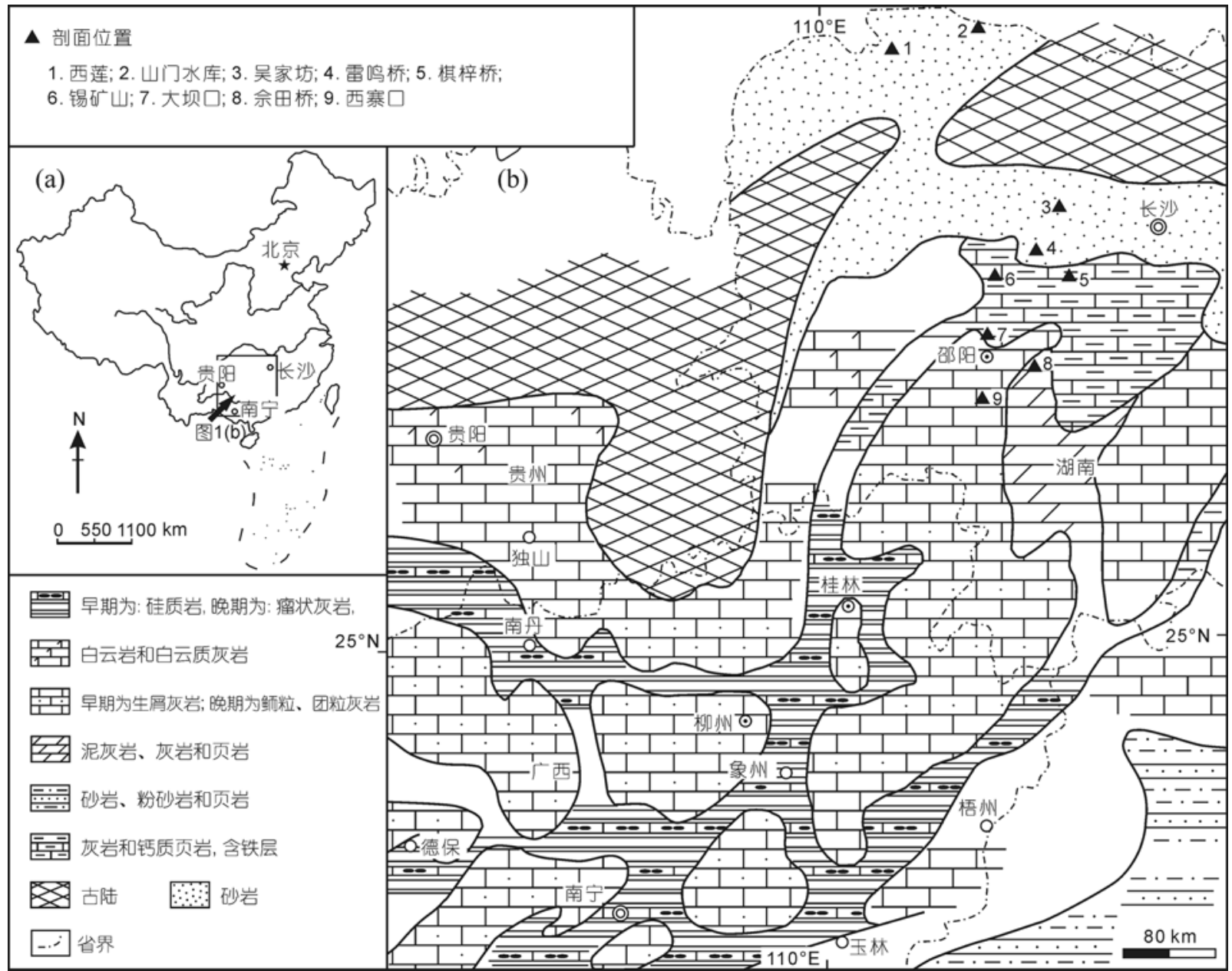

图 1 华南晚泥盆世岩相古地理图

图(b)根据Hou等 ${ }^{[10]}$, 并综合俞昌民等 ${ }^{[3]}$ 、王根贤 ${ }^{[7]}$ 和柳祖汉 ${ }^{[8]}$ 修改 
华南泥盆纪海域范围最广的时期之一.

下面以晚泥盆世为例说明湖南地区所包括的几 种沉积相.

(1) 滨岸相的砂质或砂质为主的沉积区. 自长沙 向西, 至湘西及湘西北, 包括桑植县西莲剖面、澧县 闸口山门水库剖面、桃江县的吴家坊剖面、涟源市的 雷鸣桥剖面(图 1).

湘西北的云台观组平行不整合于志留系小溪峪 组之上, 为一套灰白色、肉红色或紫红色中、厚层至 块状石英砂岩为主, 夹粉砂岩和砂质页岩, 仅产植物 化石, 属于 Protolepidodendron scharyanum-Barrandeina dusliana组合带 ${ }^{[6]}$. 黄家蹬组为灰绿色、黄灰色 砂岩、粉砂岩、砂质页岩, 夹鲌状赤铁矿层或含铁砂 岩, 含植物Leptophloeum rhombicum等、弓石燕类 (Cyrtospirifer, Tenticospirifer)-无洞贝类等腕足动物 和四射珊瑚(Pseudozaphrentis difficile)化石. 写经寺 组按岩性包括两部分: 下段为海相段, 以页岩、灰岩 为主夹赤铁矿层, 含腕足类Yunnanella sp., Ptychomaletoechia $\mathrm{sp}$.及弓石燕类; 上段为陆相或滨海相的砂 岩、页岩, 富含植物化石.

桃江县的吴家坊组以石英砂岩、粉砂岩为主, 夹 含砾砂岩、砂砾岩、砂质页岩, 所含化石以植物及鱼 类为主, 但也在某些层位夹有双壳类、腹足类及无铰 类型腕足类. 根据上下地层, 本组时代大致属于弗拉 斯期 ${ }^{[2]}$.

涟源的雷鸣桥剖面最初由湖南省地质局区测 队 ${ }^{1}$ 描述, 之后不同研究人员又进行了一些专题研究, 我们也多次对该剖面进行了实际工作, 并实测了弗 拉斯期的地层(图 2).

(2) 碳酸盐岩台地相的灰岩、白云质灰岩的沉积 区, 主要分布于湖南南部, 并被近北北东方向的台盆 相所分割. 代表性剖面包括邵阳以南的西寨口等(图 $1,2)$.

这个时期该相区的沉积体即为谭正修等 ${ }^{[5]}$ 厘定 后的棋梓桥组, 其时代跨度可从吉维期至弗拉斯期 末, 但在各地顶部时限可以不同. 主要为厚层-巨厚 层的碳酸盐岩沉积为特征, 按此定义, 图 2 中西寨口 剖面 ${ }^{2}$ 的“余田桥组”也应归于棋梓桥组. 上覆的锡矿
山组仍然以碳酸盐岩为特征, 主要区别是夹有多层 薄层至中层状泥质灰岩或泥灰岩.

(3) 以灰岩及页岩为主的潮下带混积岩相区，主 要分布于湘中新化至湘潭一带, 包括锡矿山剖面、棋 梓桥剖面.

这个相区的特点就是底栖生物化石十分丰富, 但部分地区也可能有少量的浮游生物化石, 此外就 是沉积相的变化, 例如弗拉斯期的地层可以明显分 出龙口冲组、七里江组及老江冲组等三套地层. 吉维 期的地层也可以分出下部的易家湾组和上部的棋梓 桥组, 而法门期的地层自下而上则可以分为长龙界 组、锡矿山组、欧家冲组、邵东组-孟公坳组, 例如锡 矿山剖面。

(4) 以较深水沉积为主的台盆相区, 呈北北东方 向的带状分布, 自广西延伸至湖南中部, 包括余田桥 剖面、大坝口剖面等(图 1).

该相区主要岩性为钻质泥页岩、粉砂质泥岩、 中-薄层状泥灰岩、灰岩, 局部见有硅质条带灰岩或硅 质岩. 浮游、游泳生物相对比较丰富, 包括牙形石、 竹节石, 还可能有菊石、浮游介形虫等, 除此之外, 还有底栖生物化石, 但总体数量较少, 种类也比较单 调, 例如余田桥剖面 ${ }^{[11,12]}$.

\section{2 剖面间的地层对比}

泥盆纪的地层划分和对比的主要依据以牙形石 等浮游生物为最重要. 然而, 由于环境特点, 湖南的 泥盆系底栖生物较浮游生物更加发育, 所发现的浮 游生物化石大多出现于上述台盆相区. 因此, 该相区 对湖南中、上泥盆统地层的划分和对比起着关键作用. 在缺少浮游生物标志化石时, 底栖生物珊瑚、腕足类 在这里泥盆系划分和对比中也起着重要作用.

\section{1 湘中较深水相区浮游生物及其生物带的建立}

大坝口剖面的生物带依据的是牙形石 ${ }^{3)}$. 该剖面 的棋梓桥组与“巴漆组”的界线为牙形石 $S$. hermanni 带的底界, 这也是国际泥盆系地层分会所划分的吉
1) 湖南省地质局区测队，中华人民共和国区域地质调查报告 (1:20 万涟源幅). 1973
2) 湖南省地质局区测队. 中华人民共和国区域地质调查报告 (1:20 万邵阳幅). 1977
3) 谭正修, 董振常, 曾祥洲, 等. 湖南上泥盆统的划分与对比. 湖南省地质矿产局区调所, 1992. 1-145, 图版 1-30 


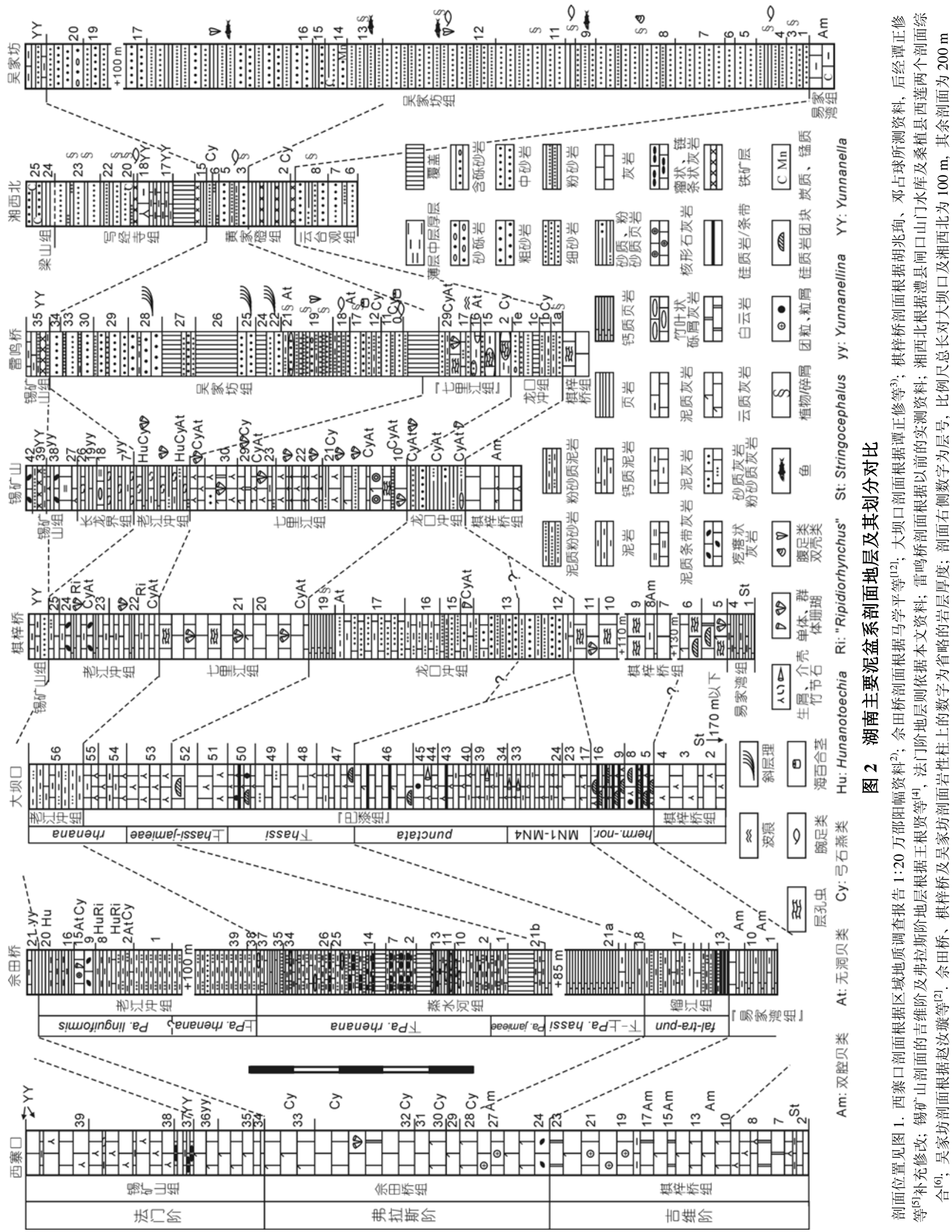


维阶上亚阶的底部 ${ }^{[9]}$, 主要特点是代表了一次明显的 海侵, 这在国际国内有许多例子, 例如桂林菜子岩剖 面 ${ }^{[13]}$. 从岩性来看, 大坝口剖面S. hermanni-Po. cristatus 带主要以中薄层硅质条带灰岩为主, 应代表海 水变深的结果. 牙形石Ancyrodella rotundiloba 的早 期类型首次出现于 17 层上部, 因而, 中-上泥盆统界 线应大致位于 17 层内或底部。谭正修等 ${ }^{3)}$ 将 $P a$. punctata带底界、下Pa. hassi 带底界、上Pa. hassi带底 界、Pa.jamieae带底界、Pa. rhenana带底界分别置于 34 层底、47 层底、51 层底、53 层底、54 层底.

马学平等 ${ }^{[11]}$ 根据牙形石、竹节石、浮游介形虫、 菊石等大致确定了余田桥剖面弗拉斯阶的牙形石生 物带. 该剖面的弗拉斯阶地层分为三组地层(图 2), 其中蒸水河组可以分为以钙质泥页岩为主的下部 $(P a$. hassi 带)及以泥页岩-泥灰岩-灰岩互层为主的上部 $(P a$. jamieae 带-下Pa. rhenana带). 而余田桥剖面的吉维阶 的“易家湾组”厚度大于 $260 \mathrm{~m}$, 主要以灰岩、泥灰岩、 泥页岩为主, 其下部(未到底)约 $110 \mathrm{~m}$ 以泥硅质岩性 为主夹泥灰岩 (马学平等 ${ }^{[12]}$, SI1 SI7); 中部约 $60 \mathrm{~m}$ 厚 的地层(SI8 SI13) 以中厚层灰岩与中薄层灰岩及泥灰 岩互层为主, 产较丰富的竹节石及腕足动物, 包括 Nowakia otomari及腕足类Bornhardtina $\mathrm{sp}$. 等, 前人在 相当层位中报道有 Stringocephalus 出现 ${ }^{[3]}$. 竹节石 Nowakia otomari在华南最早可出现于艾费尔期晚期, 例如广西崇左那艺剖面 ${ }^{[14]}$, 但在由此向北及东北的 大部分华南地区, 它一般出现于吉维阶下部, 例如广 西六景剖面产于民塘组下部 ${ }^{[15,16]}$ 、南宁郊区的罗富组 共生有腕足类Stringocephalus ${ }^{[17]}$ 等. 余田桥剖面“易 家湾组”上部约 $90 \mathrm{~m}$ (SI14 SX12), 其中下部以泥质 沉积为主, 上部特点是黑色泥页岩与泥质灰岩互层, 到顶部以灰岩为主, 含大量的保存状况一般的竹节 石, 所含腕足类以Emanuella sp. 为主, 属于双腔贝类 (ambocoeliid)-秃嘴贝类(leiorhynchid)组合带, 大致可 与大坝口剖面“巴漆组”的底部一段地层对比(图 2).

\section{2 腕足动物组合及其时代依据}

在潮下带混积岩相区中, 底栖生物组合对剖面 间的地层对比具有重要意义. 锡矿山剖面和棋梓桥 剖面所处古地理部位较为相似, 因而其沉积序列及 古生物群面貌也十分类似. 龙口冲组以砂泥质沉积 为主, 含弓石燕类腕足动物; 七里江组以灰岩沉积为 主, 甚至厚层-块状灰岩, 含珊瑚及层孔虫等造礁生
物; 老江冲组以泥页岩与灰岩互层为特点, 含丰富的 小嘴贝类、弓石燕类等腕足动物以及四射珊瑚化石.

\subsection{1 鸮头贝(Stringocephalus) 顶峰带}

该带以Stringocephalus 在华南广泛分布为标志, 除带化石外，Bornhardtina 及 Parastrophonella? mccarthyi (以前的文献中称为Leptostrophia mccarthyi) (图 3 中的 32,35) 也是该带的常见类型, 另外还包括 无洞贝类、石燕贝类等类型. 在华南, 目前已知 Stringocephalus 出现的最低层位位于艾费尔期末期Po. ensensis带之底 ${ }^{[18]}$, 但在华南仅此一处, 其他地区的 Stringocephalus 基本均位于吉维阶Po.varcus带内, 例 如广西马鞍山剖面 ${ }^{[19]}$ 、桂林菜子岩剖面 ${ }^{[20]}$ 、湖南等 地 ${ }^{[5]}$. 极少数情况下, Stringocephalus 的最高层位可位 于 Po. cristatus 带, 例如广西巴漆剖面 ${ }^{[16]}$. Stringocephalus 组合的主体部分与竹节石Nowakia otomari 带大致对应, 与四射珊瑚 StringophyllumParamixogonaria 组合及Endophyllum-Sunophyllum 组 合 ${ }^{[21]}$ 两者时代大体一致, 相当于牙形石 Po. hemiansatus-Po. varcus带.

本文所选择的几个剖面中, 该带出现于西寨口 剖面棋梓桥组底部、余田桥剖面 “易家湾组” 中下部、 大坝口剖面棋梓桥组 (该地本组约 $230 \mathrm{~m}$ 厚)下部 ${ }^{[5]}$ 、 棋棹桥剖面易家湾组等, 其他剖面上该时期的地层 或者掩盖、或者沉积相不适宜腕足类的生活.

\subsection{2 双腔贝类 (ambocoeliid)-秃嘴贝类(leiorhyn- chid)组合带}

该组合主要包括石燕贝类双腔贝科的一些分子 (例如Emanuella等: 图 3 中的 4)及小嘴贝类秃嘴贝科 的一些分子(例如Leiorhynchus 等: 图 3 中的 25). 该组 合的分布范围介于Stringocephalus顶峰带与弓石燕类 组合带之间, 以Stringocephalus 在大部分地区的消失 和弓石燕的出现为底、顶界. 但该组合的一些分子例 如双腔贝科的 Emanuella在华南从艾费尔期 (例如应 堂组 ${ }^{[16]}$ )就开始出现了; Leiorhynchus 等也可以出现于 吉维期早期的地层中 ${ }^{[12]}$. 因此, 该组合的识别要借助 于上、下两个腕足类化石带的限定. 就湖南来看, 本 组合的时限跨越了中-上泥盆统界线, 大致相当于牙 形石S. hermanni 带至Pa. punctata带. 


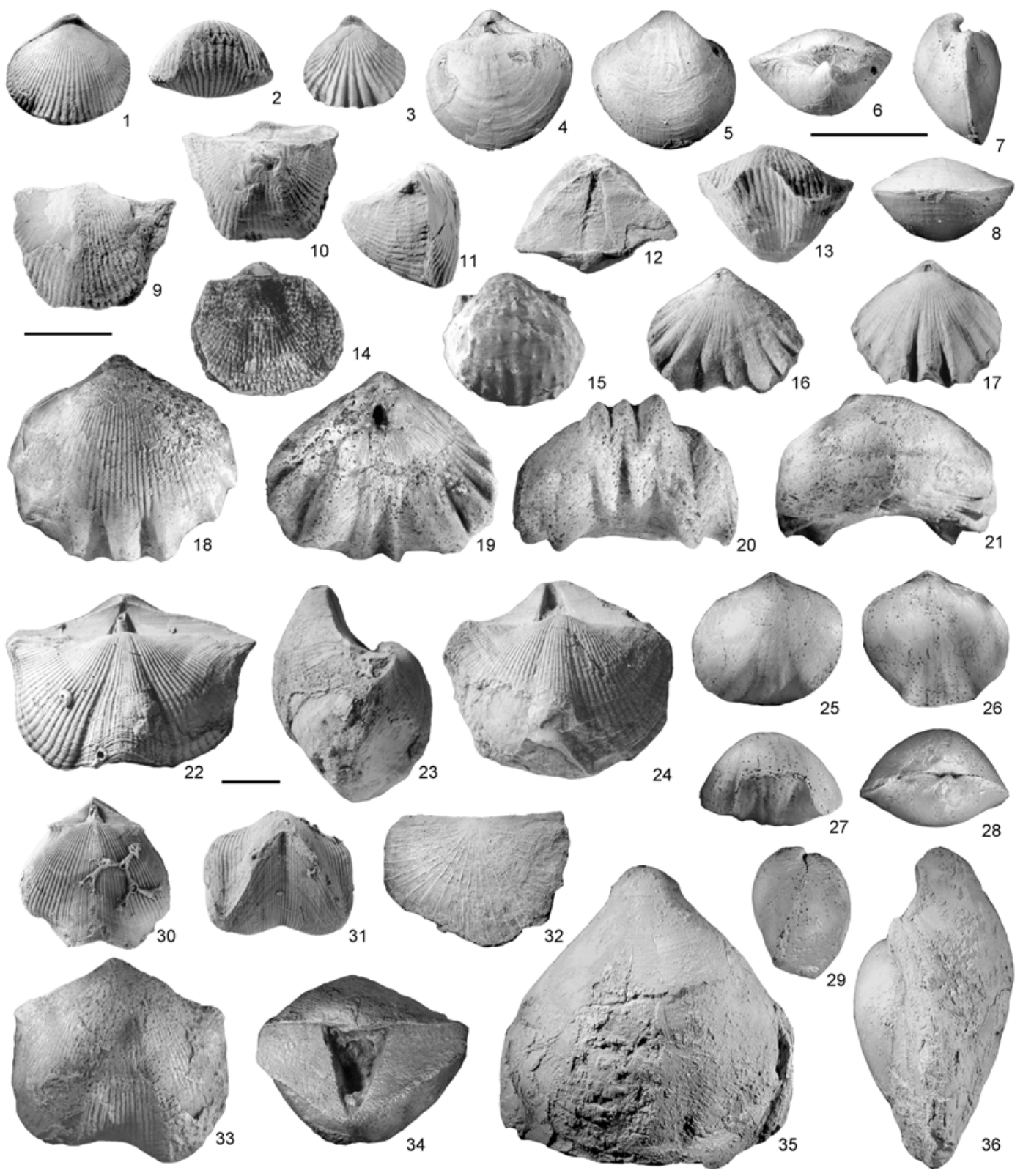

图 3 湖南中-晚泥盆世腕足动物组合一些典型代表

所有标尺均为 $10 \mathrm{~mm}$ : 上标尺为图 1 8; 中标尺为图 9 21; 下标尺为图 22 36. 1, 2, Hunanotoechia tieni Ma, 1993. 背, 前视, 标本号 XD9221, 锡矿山剖面老江冲组. 3, “Ripidiorhynchus” gamma (Tien, 1938). 背视, 标本号 PUM00051, 余田桥剖面老江冲组. 4 8, Emanuella sp. 背, 腹, 后, 侧, 前视, 标本号 PUM03064, 余田桥剖面“易家湾组”(图 2 第 1 层). 9 13, Pyramidaspirifer cf. helenae (Fenton, 1918). 背, 腹, 侧, 基面, 前视, 标本号 PUM05034, 棋梓桥剖面七里汇组. 14, Praewaagenoconcha linglingensis (Wang, 1956). 背视, 标本号 PUM 00030, 蒋家桥剖面法 门阶长龙界组近底部. 15, Leioproductus hunanensis Liu, 1982. 腹视, 标本号 PUM 00031, 蒋家桥剖面法门阶长龙界组近底部. 16, 17, Yunnanellina hanburyi (Davidson, 1853). 腹, 背视, 标本号 PUM92082, 锡矿山剖面长龙界组. 18 21, Yunanella sp. 背视, 标本号 PUM09001; 腹, 前, 后视, 标本号 PUM09002; 均为黎家坪剖面锡矿山组. 22, Sinospirifer subextensus (Martelli, 1902). 背视, 标本号 PUM 98030, 蒋家桥 剖面法门阶长龙界组近底部. 23, 24, Cyrtospirifer cf. sichuanensis Chen, 1978. 侧, 背视, 标本号 PUM93556, 锡矿山剖面老江冲组近顶部. 25 29, Leiorhynchus kwangsiensis Grabau, 1931. 腹, 背, 前, 后, 侧视, 标本号 PUM09003, 大坝口剖面 Pa.punctata 带(图 2). 30, 31, Cyrtiopsis davidsoni Grabau, 1923. 背, 前视, 标本号 PUM97001, 蒋家桥剖面法门阶长龙界组近底部. 32, Parastrophonella? mccarthyi (Grabau, 1931). 腹 视, 标本号 PUM03038, 余田桥剖面“易家湾组”(相当于吉维阶)近中部. 33, 34, Hunanospirifer wangi Tien, 1938. 腹, 后视, 标本号 PUM09004, 黎家坪剖面锡矿山组. 35, 36, Bornhardtina sp. 腹, 侧视, 标本号 PUM03049, 地点层位同图 32 
本文所选择的几个剖面中, 该组合出现于西寨 口剖面棋梓桥组中上部及“余田桥组”下部、余田桥剖 面“易家湾组”上部、棋梓桥剖面棋梓桥组、锡矿山剖 面棋梓桥组等; 雷鸣桥剖面和吴家坊剖面的吉维阶 地层也有双腔贝类分子, 但因缺少上下组合分子限 定, 不能确认其具体地层位置.

在四川龙门山剖面及广西桂林菜子岩剖面, 已 有的牙形石资料证明, 在中-上泥盆统界线之上, 大 致到Pa. punctata带顶, 有一个以小嘴贝类、无洞贝类 以及双腔贝类为主的腕足动物群; 在云南东部及贵 州南部的相当层位里也有类似的情况. 其中的腕足 动物曾被称为Yocrarhynchus-Phlogoiderhynchus组合, 它所代表的时间曾被称为土桥子时间段 ${ }^{[22,23]}$.

\subsection{3 弓石燕类(cyrtospiriferids)组合带}

在华南, 该组合以弓石燕Cyrtospirifer (图 3 中的 24)的出现为底界, 其中还有其他具褶的石燕贝类种 类, 包括Tenticospirifer, Conispirifer, Pyramidaspirifer (图 3 中的 9)等, 此外还有小嘴贝类及无洞贝类, 例如, Hypothyridina, Radiatrypa yangi, Spinatry- pina lungkouchungensis以及许多从前一个组合带延伸过 来的分子 ${ }^{[22 ~ 26]}$. 在华南, 该组合出现的层位大致位 于弗拉斯期中期 $P a$. hassi 带开始 ${ }^{[2]}$, 终止于弗拉斯/ 法门界线处, 其上为准云南贝(Yunnanellina)-中国石 燕(Sinospirifer)组合带.

本文所选择的几个剖面中, 该组合分布十分广 泛, 出现于西寨口剖面“余田桥组”中上部、棋梓桥剖 面、锡矿山剖面、雷鸣桥剖面的龙口冲组、七里江组 及老江冲组或吴家坊组以及湘西北的黄家蹬组等. 在较深水相区, 弓石燕类则出现于弗拉斯期的后期 地层中, 例如余田桥剖面, 这个时期其岩相与浅水混 积岩相区的沉积比较类似, 这种情况一直持续到法 门期. 实际上, 与老江冲组同期地层在湘中有着类似 的动物群, 可以称为 Hunanotoechia-“Ripidiorhynchus”亚组合带(图 3 中的 1 和 3), 以丰富的小嘴贝 类-无洞贝类-弓石燕类腕足动物为特征, 其中无洞贝 类基本为从先前延续过来的, 而弓石燕类则出现一 些新的从其他地区迁移来的类型, 例如, Adolfia, Eodmitria, Mennespirifer等, 本亚组合的时代大致相 当于上 $P a$. rhenana带至 $P a$. linguiformis带. 而在此之 下的弓石燕组合为下亚组合 (未命名), 以 conispiriferid类的Conispirifer和Pyramidaspirifer、弓石燕类、
无洞贝类等为特征, 其时代大致相当于 $P a$. hassi带至 下Pa. rhenana带 ${ }^{[23]}$.

\subsection{4 准云南贝(Yunnanellina)- 中国石燕(Sinos- pirifer)组合带}

该带以小嘴贝腕足类Yunnanellina (图 3 中的 17) 的普遍出现为特征, 除Yunnanellina 小嘴贝类外, 还 有大量的Ptychomaletoechia、弓石燕类及长身贝类等, 包括Sinospirifer (图 3 中的 22), Plicapustula, Lamarckispirifer, Pseudocyrtiopsis, Productella, Praewaagenoconcha (图 3 中的 14)、Leioproductus (图 3 中 的 15)等 ${ }^{[27,28]}$. Cyrtiopsis (图 3 中的 30)和Platyspirifer 虽然数量不多, 但壳体很独特. 在湘中南, 该组合出 现于锡矿山组下部或与此相当的长龙界组及锡矿山 组的兔子塘段, 时代范围大致相当于牙形石 $P a$. triangularis带至上Pa. crepida带 ${ }^{[29]}$.

\subsection{5 云南贝(Yunnanella)- 湖南石燕 (Hunanosp- irifer)组合带}

该组合以小嘴贝腕足类Yunnanella (图 3 中的 18 和 19)的大量繁盛为特点, 此外, 还常见有个体较大 的弓石燕类等, Tien ${ }^{[1]}$ 描述了许多类型, 包括Hunanospirifer (图 3 中的 33)、“Tenticospirifer”等. 在湘中, 该组合分布于泥塘里铁矿层及其上的玛牯脑段, 时 代范围大致相当于牙形石最上 $P a$. crepida带至 $P a$. marginifera带顶部.

该组合的分布十分广泛, 几乎湖南所有有泥盆 系地层的地方, 均有其分布.

\section{3 海平面变化与地层对比}

华南从艾费尔期后期的海退之后为一个连续海 侵的阶段 ${ }^{[30]}$, 但自下Po. varcus带 (Po. rhenanus的首 现层位)华南的裂谷活动明显加强, 并最终导致了台沟相间的网状格局(图 1). 实际上, 华南的这次裂谷 活动加强的开始时间刚好与国际地层委员会泥盆系 分会所确认的下-中吉维亚阶的界线一致 ${ }^{[31]}$. 在此过 程的初期, 台地相的区域有可能抬升, 造成海平面降 低, 例如贵州独山剖面的宋家桥砂岩段; 而台沟相 (或台盆相)则海水加深, 例如在大乐巴漆剖面, 由下 面的东岗岭组(相当于Bai等 ${ }^{[16]}$ 的鸡德段)的泥灰岩、 泥质灰岩及灰岩突然变为其上的巴漆组的硅质条带 薄板状灰岩. 在湖南, 这个时期大致相当于 “巨口铺 
组” (即本文的易家湾组)与棋梓桥组的交界附近, 例 如棋梓桥剖面、大坝口剖面、巨口铺剖面 ${ }^{[5]}$. 在广西, 吉维期中期的海退早已为大多数人所认识, 例如吴 诒等 ${ }^{[32]}$, 这次海退的时间应为牙形石上Po. varcus 带, 且随之而来的是牙形石 $S$. hermanni 带初期的海侵 ${ }^{[13]}$, 而这个层位也是国际地层委员会泥盆系分会所确认 的中-上吉维亚阶的界线 ${ }^{[31]}$. 在湖南, 比较清楚的是 较深水相的一些剖面, 例如大坝口剖面(为棋梓桥组 厚层灰岩与“巴漆组”薄层灰岩夹硅质条带的岩性界 线)和临武香花岭剖面(为黄公塘白云岩与 “巴漆组”或 “新邵组”的分界 $)^{3)}$; 在碳酸盐岩台地相区, 因为相应 的层位位于棋梓桥组大套灰岩地层内, 没有详细的 牙形石及岩性分层资料, 难以识别该海侵事件, 例如 棋梓桥剖面; 但在新邵县巨口铺(=寺脚下)剖面, 距 棋梓桥组底部约 $220 \mathrm{~m}$ 的 15 18 层以中薄层为主 ${ }^{[5]}$, 含有较多的牙形石, 而上下岩层不含牙形石, 其中 15 16 层均含有Po. dubius及Po. xylus xylus 等 ${ }^{3)}$. Aboussalam ${ }^{[33]}$ 以全球资料为基础总结了围绕Taghanic 事 件前后的牙形石分布, 其中Po. dubius 始现于 $S$. hermanni 带, 这在国内情况亦是如此, 例如广西马鞍 山剖面 ${ }^{[19]}$ 、广西菜子岩剖面 ${ }^{[20]}$ 、湖南大坝口剖面、 香花岭剖面 ${ }^{3)}$. 在 15 层之下为厚层-块状的白云质灰 岩、泥晶灰岩, 见有岛眼构造及白云岩. 因此, 从沉 积及牙形石证据看, 巨口铺剖面 15 层开始代表 $S$. hermanni 带的海侵, 而在此之下的地层则代表了上 Po. varcus带的海退, 与菜子岩剖面一致. 这样看来, S. hermanni 带初期的这次海侵同时出现于深水台盆 相区及浅水台地相区, 可能反映了一次真正的海平 面变化, 而构造活动可能仅起次要作用.

自吉维期晚期的 $S$. hermanni $i$ 带的海侵之后到吉 维期末期, 海平面总体趋势是降低 ${ }^{[34]}$, 但在不同地区 表现不同. 在原来裂谷带的区域, 海水可能是加深或 变化不大的, 例如广西鹿寨寨沙剖面的榴江组在吉 维期末期开始沉积 ${ }^{[35]}$, 湖南余田桥剖面的榴江组也 基本是同时开始沉积的 ${ }^{[12]}$. 台地相区的中-上泥盆统 界线主要以岩性组段来区分, 原因是在该界线上下 的底栖生物群缺乏能够准确确定时代的种类. 但就 目前大家较为公认的华南台地相区中-上泥盆统界线 来看, 吉维期末期有过一次规模不等的海退, 例如云 南盘溪剖面-打得组下段与中段之交出现陆生植物化 石及砂岩 ${ }^{[22,36]}$, 贵州独山剖面独山组鸡窝寨段顶部 出现白云石化灰岩或白云岩, 而其上的望城坡组贺
家寨段底部则出现砂岩 ${ }^{[37]}$ 或含砾泥灰岩, 广西桂林 附近的诸多剖面缺失吉维阶上部的地层, 甚至于弗 拉斯阶下部地层也有缺失 ${ }^{[38]}$. 一般认为湖南混积岩 台地相区的棋梓桥组与上覆的龙口冲组界线即为中上泥盆统界线, 例如棋梓桥剖面、锡矿山剖面等 ${ }^{[4,39]}$. 这里的棋梓桥组与龙口冲组的界线代表了一次岩相 的突变, 而且棋梓桥组的顶面往往有风化剥蚀等特 征, 例如雷鸣桥剖面; 此外, 龙口冲组含有弓石燕类, 这类腕足动物往往在弗拉斯期中期才开始在华南出

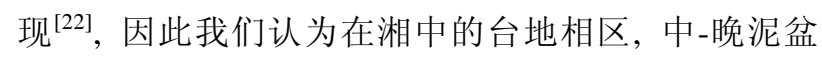
世之交也经历了一次海平面明显降低的过程, 并导 致湖南北部弗拉斯期早期地层的缺失, 使得含弓石 燕类地层直接覆盖在中泥盆统地层之上(图 2).

晚泥盆世弗拉斯期中后期, 华南台盆相区与台 地相区的的沉积所代表的海平面变化基本一致. 大 的趋势是弗拉斯期代表了一个大的海侵-海退旋回, 其中还包括了许多次级的旋回; 弗拉斯期中期 $P a$. hassi 带的海侵对湖南的生物群有较大的影响, 一是 在台盆相区出现了菊石类Mesobeloceras?及浮游介形 虫, 例如余田桥剖面 ${ }^{[11,12]}$, 二是在浅水台地相区出现 了弓石燕类腕足动物群, 例如棋梓桥、锡矿山等许多 剖面(图 2); 至下Pa. rhenana带可能达到了泥盆纪的 最大海侵期 ${ }^{[30]}$, 而这次海侵在湖南导致出现了 Manticoceras 等菊石及牙形石Pa. cf. semichatovae, 这 类牙形石广泛分布, 甚至是一些浅水相区 ${ }^{[9]}$. 弗拉斯 期末期则为广泛的海退, 这在近岸台地相区尤其明 显, 表现为大套的砂岩沉积等, 例如雷鸣桥剖面(图 2). 湖南法门期的海平面变化在湘中地区表现非常明 显, 例如锡矿山剖面 ${ }^{[30]}$, 包括法门期早期的海平面低 位时期(详见第 3 节)、玛牯脑海侵、欧家冲海退及邵 东海侵.

吴家坊与雷鸣桥两个剖面距离较近, 而且弗拉 斯期的时候又处于同一岩相区, 其沉积层序完全可 以对比, 这就是吉维期地层沉积之后, 开始了碎屑岩 沉积, 并且应大致等时, 其次两个剖面吴家坊组均为 含Yunnanella 腕足类的法门阶锡矿山组所覆盖, 这样 限于吉维阶和法门阶之间的地层可以对比(图 2). 虽 然吴家坊剖面的吴家坊组没有发现可以用来进行更 加详细生物地层对比的牙形石或底栖生物化石, 但 在不同层位出现有双壳类、腕足类、腹足类、鱼类及 植物等化石, 其中 1 12 层(322.4 m 厚) 见有多层海相 
生物化石夹层, 大致可与龙口冲组及“七里江组”对 比; 而 13 20 层(392 m 厚)仅其下部含有少量化石层 位, 而上部(17 20 层, $180.4 \mathrm{~m}$ 厚)以石英砂岩至砂砾 岩为主, 不含化石, 13 20 层大致可与雷鸣桥剖面的 吴家坊组进行对比(图 2). 这种向上变粗层序也见于 湘西北的黄家蹬组, 区别是其上部仍有腕足动物化 石.

\section{3 湖南中-晚泥盆世古地理格局的演变}

本节中的几幅古地理图基本岩性及化石资料为 湖南区域地质测量队在 20 个世纪 60 70 年代所完成 的 1:20 万地质填图报告, 以及后来的一些总结文献, 例如谭正修等 ${ }^{3)}$ 、谭必祥 ${ }^{4)}$ 、王根贤 ${ }^{[7]}$ 等. 使用资料前, 对有些化石清楚的剖面的时代进行了重新解释.

\section{1 吉维期早、中期古地理}

这个时期相当于腕足类鸮头贝顶峰带及牙形石 Po. hemiansatus 带至Po. varcus 带. 滨岸相的砂质沉 积区主要分布于湖南西北部(图 4(a)), 为云台观组. 武陵古陆和幕阜古陆之间可能存在一个海水通道, 使得这里与湖南中南部的海域互相贯通. 湖南南部 主要为碳酸盐岩台地(包括易家湾组及部分棋梓桥 组), 但为两个近南北向的台沟所切割. 另外在永州 南北分别有两个分支, 可能相当于与桂林以东伸出 的分支(图 1)贯通前的踓形(最终也未能完成贯通). 湖南中部长沙-湘潭向西至新化-安化一带主要为潮 下带泥灰岩相区, 大致相当于易家湾组的沉积, 其中 底栖化石比较丰富.

\section{2 吉维期晚期古地理}

这个时期相当于腕足类双腔贝类-秃嘴贝类组合 带早期及牙形石 S. hermanni 带至吉维期末. 与吉维 期早中期古地理大的格局基本相似, 主要区别是西 部的碳酸盐岩台地范围扩大到新化至安化一带(图 4(b)), 棋梓桥组是其沉积的主体; 幕皁古陆的南缘则 出现许多砂质及泥页岩沉积, 例如吴家坊剖面. 这样 使得原泥灰岩沉积区的范围大大缩小. 台盆裂谷地 带则以薄层灰岩、泥灰岩沉积为主, 含许多浮游生物 化石, 例如余田桥剖面(既含有底栖生物化石, 又含
有浮游的竹节石), 湖南东部台盆相的南部新田至嘉 禾之间的地带还出现了硅质岩的沉积.

\section{3 弗拉斯期早期至牙形石 Pa. punctata 带古地理}

这个时期相当于双腔贝类-秃嘴贝类组合带晚期, 自吉维期/弗拉斯期界限至牙形石 Pa. punctata 带. 根 据前面的腕足动物组合的时代分析及剖面对比, 弓 石燕类的出现应该代表了弗拉斯期中期左右. 在湖 南北部的许多剖面中, 弓石燕类直接出现在中-上泥 盆统界线之上, 说明缺失了弗拉斯期早期的地层, 包 括湘西北、雷鸣桥、锡矿山、棋梓桥等(图 2). 基于 这样的认识, 本文认为这个时期的湖南其沉积范围 大大缩小. 湖南北部在这个时期基本属于陆地，即幕 阜古陆与武陵古陆连成了一片(图 5(a)), 此外, 湖南 东南炎陵南北一带也暴露成陆, 甚至碳酸盐岩台地 内部也出现局部的暴露区而未能接受沉积, 例如东 安以西一带的依山铺等地、道县东南一带等.

与浅水相区抬升变浅相反的是，台盆或台沟地 带的硅质岩沉积相当普遍, 包括新化以南的定河冲 一带、永州南北的两个台盆分支以及东部台盆相区的 南端(图 5(a)). 碳酸盐岩台地相区的岩组包括“余田桥 组”、“马鞍山组”等, 张纯臣等 ${ }^{[6]}$ 则使用棋梓桥组代表 吉维阶至弗拉斯阶的厚层至块状灰岩沉积体.

\section{4 弗拉斯期中晚期古地理}

这个时间段相当于弓石燕类组合带及牙形石 $P a$. hassi 带至 Pa. linguiformis 带, 以弓石燕类开始在华 南底栖相区的广布为特征, 这是 $P a$. hassi 带海侵的 结果, 导致海域范围又扩展到了湘西北. 该期岩相相 对比较复杂, 近岸砂质为主的沉积区分布在沿幕阜 古陆和武陵古陆的边缘(图 5(b)). 桑植以北的洪家峪西莲一带以页岩及少量砂岩为特征. 湘潭向西, 经娄 底-新化以北, 至安化, 然后向南至怀化以东的铜湾 一带, 主要为灰岩、泥灰岩及砂岩混积岩沉积区. 湖 南东部做县至炎陵一带则为砂页岩、粉砂岩、页岩及 砂质灰岩沉积区. 其余部分仍保留了吉维期的碳酸 盐岩台地及台盆格局.

\section{5 法门期早期古地理}

本期相当于准云南贝-中国石燕组合带及牙形石

4) 谭必祥. 第六章 泥盆系. 见: 湖南省地质科学研究所, 编著. 湖南地层, 1979. 77一94 

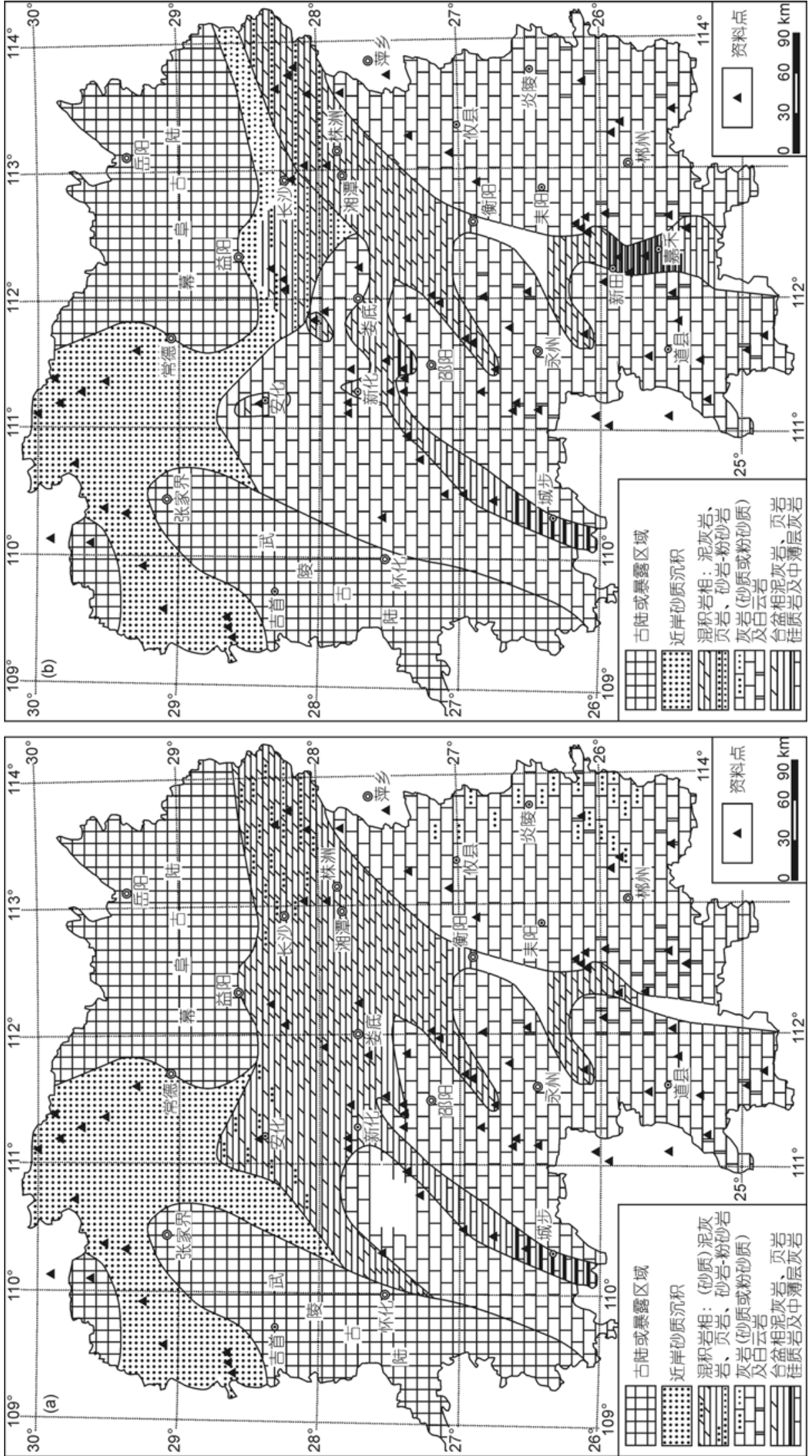

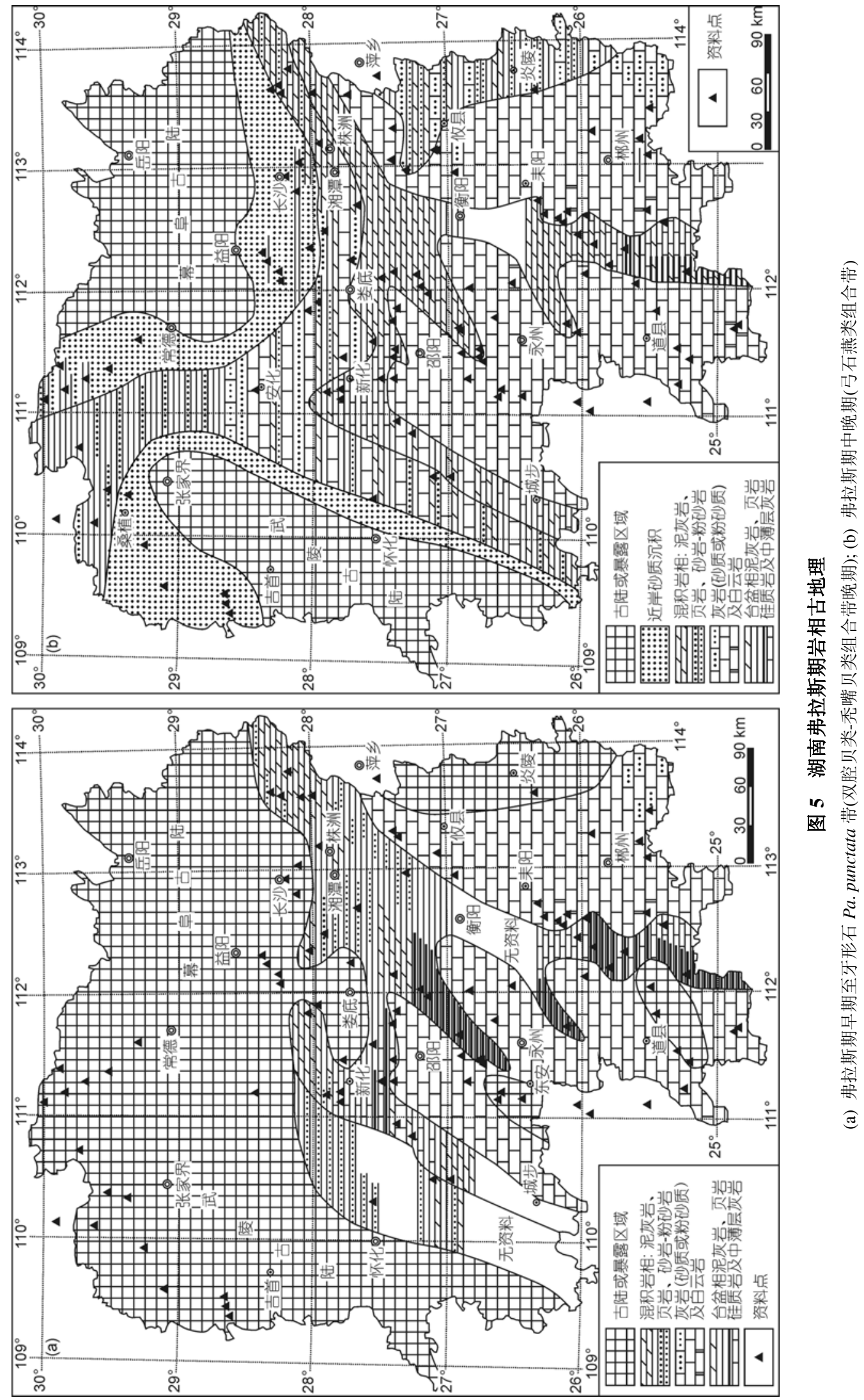
$P a$. triangularis带至上 Pa. crepida带. 准云南贝 (Yunnanellina) 在湘中非常丰富, 然而, 与弗拉斯期弓 石燕类及法门期的弓石燕类及Yunnanella的地理分布 相比则比较局限, 这在图 2 及 6(a)中可以明显看到. 其原因不应该是环境因素的影响, 因为这几种类型 都有着相似的生活环境. 本文认为主要原因是弗拉 斯期末期广泛的海退, 使得湖南北部大部分地区暴 露, 即使法门期初期可能有过海侵, 但主要限于湖南 中南部的低地地带, 并未能够恢复到弗拉斯期中晚 期的状况. 结果是原有的古陆范围扩大, 甚至在湖南 南部碳酸盐岩台地弗拉斯期早期孤立的小块暴露地 区(图 5(a)) 在这时也联合了起来(图 6(a)). 值得注意的 是, 虽然湘西北大部分地区可能缺乏沉积而没有出 现Yunnanellina分布, 但根据 1:20 万区调报告, 桑植 西莲地区可能有发现, 可惜未见其图示. 杨德雨 ${ }^{[40]}$ 所 图示的来自湖北长阳写经寺组的 Yunnanellina triplicata var. latiformis Tien难以确定其归属, 主要原 因是, 同样大小、确切的湖南Yunnanellina标本的前缘 放射肋已经非常强壮了. 王淑敏 ${ }^{[41]}$ 所图示的采自湖 北宣恩及长阳的Yunnanellina hanburyi mut. sublata Tien应该属于真正的Yunnanellina. 这样的话, 武陵古 陆与幕皁古陆之间仍然需要有个海水通道存在. 另 一个孤立地点是长沙东南的团田, 根据浏阳幅 $1: 20$ 万区测报告 ${ }^{5}$ 是有Yunnanellina 的, 因缺乏实际材料 本文未能确定, 暂按向南存在海水通道处理.

这个时期的古地理与弗拉斯期中晚期相比, 除 陆地范围较大以外, 从吉维期存在的东、西两条近南 北向的台沟已经基本没有了影响, 这样, 这个时期的 岩相比较简单, 可分为北部的泥灰岩相区和南部的 较纯的灰岩相区(图 6(a)). 其中泥灰岩相区的地层厚 度可以相差很大, 尤其是在一些先前曾为较深水地 区的剖面, 例如余田桥(图 1)及其以南的蒋家桥剖面 长龙界组厚度均大于 $200 \mathrm{~m}$, 而锡矿山剖面的长龙界 组则仅约 $50 \mathrm{~m}$.

\section{6 法门期中期古地理}

本期相当于云南贝-湖南石燕组合带及牙形石最 上Pa. crepida 带至 Pa. marginifera 带顶部. 与
Yunnanellina 的分布形成鲜明对照的是, 云南贝 (Yunnanella) 在湖南的分布十分广泛, 几乎湖南所有 有泥盆系地层的地方，均有其分布. 这个时期的海域 范围又恢复到了弗拉斯期中晚期的规模(图 6(b)), 只 是湘中南地区的岩相更加均一, 均以灰岩沉积为主, 北部泥灰岩略多一些, 但即使到湘南地区，也有可能 会出现少量的泥质含量. 另一个为益阳、长沙、株洲、 敒县、炎陵、汝城一带以泥灰岩、页岩、粉砂岩、砂 岩为主的沉积区; 汶阳东北一带为以砂质为主的沉 积区, 个别地点可能含 Yunnanella, 例如汶阳草坪.

湘西北地区可以分两部分, 自桑植西莲向东至 澧县山门水库为泥灰岩、泥页岩沉积区，其中东部的 泥页岩、粉砂岩含量较西部增多; 另一部分为沿武陵 古陆以北区域(图 6(b)), 弗拉斯期的黄家蹬组直接为 二叠系地层所覆盖, 推测与弗拉斯期中晚期一样, 仍 为砂质沉积, 后期遭受剥蚀.

\section{4 结论}

在对前人发表和未发表资料详细分析的基础上, 并结合我们自己过去多年来的实际工作积累, 本文 总结了湘中吉维阶及弗拉斯阶较深水相区的生物带 以及台地相区吉维期至法门期中期的五个腕足动物 生物带标志、内容、分布及其与此对应的大致牙形石 带. 华南主要中-晚泥盆世地层剖面的岩相变化及牙 形石带分析对比表明，吉维期有两次明显的海平面 变化事件, 其时代分别对应于下 Po. varcus 带的中部 和 S. hermanni 带的初期. 前者可能主要与华南的裂 谷活动加强有关, 结果是裂谷带水体的普遍加深, 但 部分台地相区则因抬升使得水体反而变浅; 后者海 平面的上升在台盆及台地相区均有岩石学上的证据. 这两个层位均是国际地层委员会泥盆系分会所确认 的下-中吉维亚阶、中-上吉维亚阶之间的界线. 与台 盆相区水体可能加深的情况不同，湖南台地相区吉 维期末期和弗拉斯期末期可能出现了规模较大的海 平面降低, 并分别导致弗拉斯期早期和法门期早期 许多地区的暴露，从而缺失同期的沉积及所包含的 生物带. 前人的认识可能与此观点不一定相同, 例如

5) 湖南省地质局区测队，中华人民共和国区域地质调查报告 (1:20 万汶阳幅), 1976 

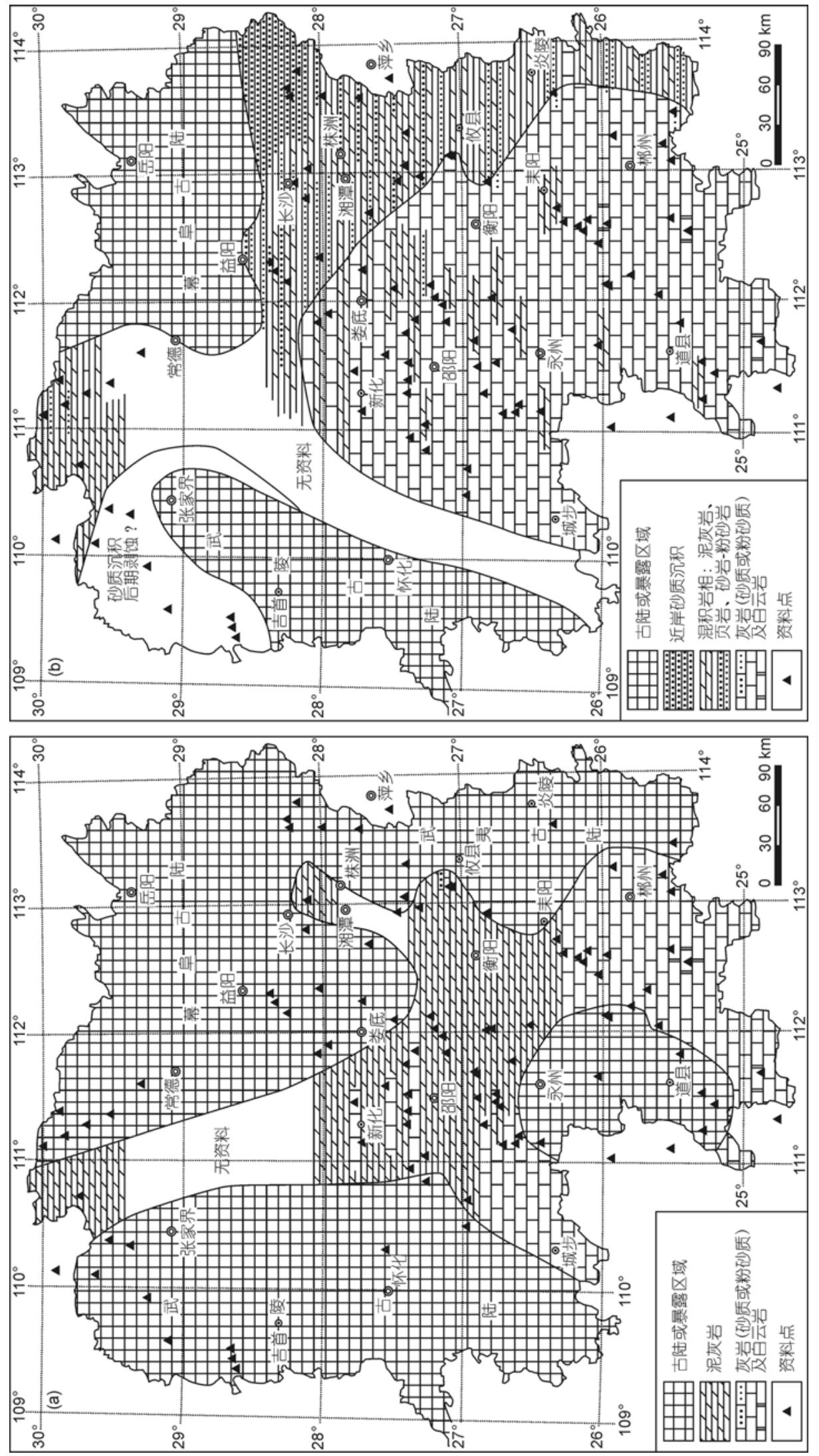

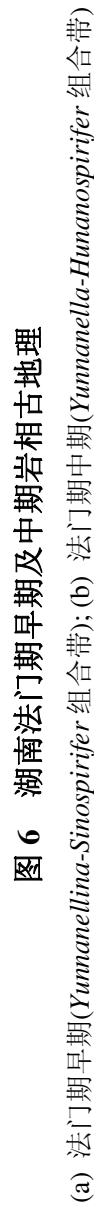


认为台地相区中-上泥盆统之间的沉积是连续的, 对小 嘴贝类腕足动物 Yunnanella 与 Yunnanellina 分布范围的
明显差别也没有进行解释. 因此, 我们希望今后有更 多的新资料对本文一些观点的正确与否加以验证.

致谢本文引用了诸多前人资料, 除所列公开发表的外, 还有许多内部资料, 包括 $1: 20$ 万区测报告以及后来的一些 总结性论著, 对此表示诚挚谢意. 对匿名评阅人所提的意见及建议亦表示由衰的感谢. 湖南的野外工作过程 中, 曾得到过湖南区域地质调查所谭正修、湖南科技大学柳祖汉等的指导以及北京大学白志强、孙元林、王 德明和许多学生的帮助.

\section{参考文献}

1 Tien C C. Devonian brachiopoda of Hunan. Palaeontol Sin-New Ser B, 1938, 4: 192

2 赵汝璇, 张采凡, 夏志芬, 等. 湖南的泥盆系. 见: 中国地质科学院地质矿产研究所, 主编. 华南泥盆系会议论文集. 北京: 地质出 版社, 1978. 68-89

3 俞昌民, 许汉奎, 彭䩀, 等. 湖南的泥盆系及含矿特征. 见: 菱铁矿矿床学术会议论文集编辑组, 编. 菱铁矿矿床学术会议论文集. 北京: 科学出版社, 1983. 262-298

4 王根贤, 景元家, 庄锦良, 等. 湘中锡矿山地区泥盆纪-早石炭世地层系统. 湖南地质, 1986, 5(3): 48一65; 5(4): 36-50

5 谭正修, 董振常, 唐晓珊. 论棋梓桥灰岩. 地层学杂志, 1987, 11: 77-90

6 张纯臣, 谭正修, 朱伦杰, 等. 全国地层多重划分对比研究(43) 湖南省岩石地层. 武汉: 中国地质大学出版社, 1997. 1一 192

7 王根贤. 湖南泥盆纪生物礁. 见: 范嘉松, 主编. 中国生物礁与油气. 北京: 海洋出版社, 1996. 117-140, 图版 1一6

8 柳祖汉. 高密度流与湖南泥盆纪沉积相分异. 地质科学, 2004, 39: 18-26

9 侯鸿飞, 马学平. 国际泥盆系 GSSP 与华南泥盆系划分. 地层学杂志, 2005, 29: 154一 159, 164

10 Hou H F, Ji Q, Wang J X. Preliminary report on Frasnian-Famennian events in South China. Canad Soc Petrol Geol Mem, 1988, 14: 63-69

11 马学平, 孙元林, 白志强, 等. 湘中余田桥剖面上泥盆统弗拉斯阶地层研究新进展. 地层学杂志, 2004, 28: 369一 374, 图版 1

12 马学平, 白志强, 孙元林, 等. 余田桥剖面一一中国上泥盆统余田桥阶层型剖面: 岩性划分及生物地层. 见: 中国地质科学院地层古 生物论文集编委会, 编. 地层古生物论文集, 第 28 辑. 北京: 地质出版社, 2004. 89-110

13 李华, 马学平, 韦龙明. 广西菜子岩剖面中上泥盆统界线附近沉积相与海平面变化一一兼论华南吉维期中期的海退及时间. 古地理 学报, 2009, 11: 503-512

14 阮亦萍, 穆道成. 广西泥盆纪竹节石. 见: 中国科学院南京地质古生物研究所, 编. 中国科学院南京地质古生物研究所集刊, 26 号. 北京: 科学出版社, 1989. 1-197, 图版 1-28

15 广国敦, 赵明特, 陶业斌. 中国海相泥盆系标准剖面一一西六景泥盆系剖面. 武汉: 中国地质大学出版社, 1989. 1一 155 , 图版及 说明 $1-48$

16 Bai S L, Bai Z Q, Ma X P, et al. Devonian events and biostratigraphy of South China. Beijing: Peking University Press, 1994. 1-303, 45 pls

17 钟铿, 吴诒, 殷保安, 等. 广西的泥盆系. 武汉: 中国地质大学出版社, 1992. 1-384, 图版 1-16

18 Sun Y L. Systematic Paleontology, Part 2. New brachiopods across the Eifelian-Givetian boundary. In: Bai S L, Bai Z Q, Ma X P, et al, eds. Devonian Events and Biostratigraphy of South China. Beijing: Peking University Press, 1994. 196-198

19 侯鸿飞, 季强, 鲜思远, 等. 广西象州马鞍山中-上泥盆统界线. 北京: 地质出版社, 1986. 1-137, 图版 1一-49

20 Li H, Ma X P, Wei L M. A Middle-Upper Devonian boundary section in the open platform, platform margin facies of Guilin, South China. Acta Geol Sin-Engl Ed, 2009, 83: 524-534

21 廖卫华, 马学平. 华南浅海相泥盆系吉维特阶和弗拉阶四射珊瑚组合特征. 古生物学报, 2007, 46: 213一224

22 Ma X P, Becker R T, Li H, et al. Early and Middle Frasnian brachiopod faunas and turnover on the South China shelf. Acta Palaeontol Polon, 2006, 51: 789-812

23 Ma X P. Spiriferide brachiopods from the Frasnian (Devonian) of the Dushan area, southern Guizhou, China. Acta Palaeontol Sin, 2009, 48: $611-627$

24 Ma X P, Day J. Revision of Tenticospirifer Tien, 1938, and similar spiriferid brachiopod genera from the Late Devonian (Frasnian) of Eurasia, North America, and Australia. J Paleontol, 2000, 74: 444-463

25 王君慧, 马学平. 湘中上泥盆统弗拉斯阶两腕足动物及其地质意义. 现代地质, 2003, 17: 251一258, 图版 1一2

26 Ma X P, Copper P, Sun Y L, et al. Atrypid brachiopods from the Upper Devonian Wangchengpo Formation (Frasnian) of Southern Guizhou, 
China-Extinction patterns in the Frasnian of South China. Acta Geol Sin-Engl Ed, 2005, 79: 437—452

27 Ma X P, Sun Y L, Hao W C, et al. Rugose corals and brachiopods across the Frasnian-Famennian boundary in central Hunan, South China. Acta Palaeontol Polon, 2002, 47: 373-396

28 Ma X P, Day J. Morphology and revision of Late Devonian (Early Famennian) Cyrtospirifer (Brachiopoda) and related genera from South China and North America. J Paleontol, 2007, 81: 286-311

29 Ma X P, Sun Y L. Brachiopod faunal successions and the subdivision of the Famennian in South China. Subcomm Devonian Strat Newsl, 2008, 23: 32-34

30 Ma X P, Liao W H, Wang D M. The Devonian system of China, with a discussion on sea-level change in South China. Geol Soc London Spec Publ, 2009, 314: 241-262

31 Bultynck P, Gouwy S. Reference sections for the middle Givetian substage. Subcomm Devonian Strat Newsl, 2008, 23: 21-31

32 吴诒, 枈一鸣, 杜远生. 华南泥盆纪层序地层及海平面变化. 武汉: 中国地质大学出版社, 1997. 1-110

33 Aboussalam Z S. Das "Taghanic-Event” im höheren Mittel-Devon von West-Europa und Marokko. Mümstersche Forschungen zur Geol Paläontologie, 2003, Heft 97: 1-330, 28 pls

34 Wu Y. Study on Devonian sequence stratigraphy and sea-level change in Guangxi (in English with Chinese Summary). Guangxi Geol, 1996, 9: $54-69,78$

35 殷保安, 彭金兰. 五、上泥盆统岩石地层. 见: 钟锃等, 编. 广西的泥盆系. 武汉: 中国地质大学出版社, 1992. 149-195

36 云南省区域地层表编写组. 西南地区区域地层表, 云南省分册. 北京: 地质出版社, 1978. 1-438

37 廖卫华, 许汉奎, 王成源, 等. 西南地区几个泥盆系基础剖面的论述. 见: 中国科学院南京地质古生物研究所, 编著. 西南地区碳酸 盐生物地层. 北京: 科学出版社, 1979. 221-249

38 李镇梁. 广西泥盆纪至早石炭世地层的平行不整合. 南方国土资源, 2005, 11: 24-29

39 侯鸿飞, 王士涛. 中国地层(7): 中国的泥盆系. 北京: 地质出版社, 1988. 1-348

40 杨德网. 腕足动物门. 见: 地质矿产部宜昌地质矿产研究所, 冯少南, 许寿永, 等, 编. 长江三峡地区生物地层学(3): 晚古生代分册. 北京：地质出版社, 1984. 203-239

41 王淑敏. 腕足动物门. 见：湖北省区域地质测量队，编著. 湖北省古生物图册. 武汉：湖北科学技术出版社, 1984. 128一236 